\title{
Percutaneous Transluminal Angioplasty of a Totally Occluded Venous Bypass Graft: A Challenge That Should Be Resisted
}

Pim J. de Feyter, MD, Patrick Serruys, MD, Marcel van den Brand, MD, Hannie Meester, Kevin Beatt, MD, and Harry Suryapranata, MD

D) ercutaneous transluminal angioplasty is an accepted treatment for stenoses of bypass grafts ${ }^{1,2}$ and for total coronary artery occlusions. ${ }^{3-5}$ It follows that the same treatment would also be appropriate for total occlusions of saphenous aortocoronary bypass grafts. This report describes our clinical experience with attempted dilatation of totally occluded saphenous bypass grafts.

Of the 2,679 consecutive patients referred for percutaneous transluminal coronary angioplasty at the Thoraxcenter, Rotterdam, between September 1980 and December 1988, 96 patients underwent percutaneous transluminal angioplasty of an obstruction in a saphenous aorta coronary bypass graft. This report describes the outcome of attempted angioplasty in 15 patients, 12 men and 3 women, who presented with total occlusion of a venous bypass graft. The baseline clinical characteristics are listed in Table I. The mean age was $57 \pm 9$ years (range 42 to 73). Most patients had significant narrowings in 3 major coronary arteries.

Eleven patients received an aortocoronary circular sequential saphenous vein bypass graft. The number of anastomoses ranged from 2 to 6/patient (mean $4 \pm 1$ ). A proximal occlusion was located between the connection of the aorta and the first anastomosis, a midocclusion was located after the first anastomosis and before the

From the Catheterization Laboratory, Thoraxcenter, Erasmus University, Postbus 1738, 3000 DR Rotterdam, the Netherlands. Manuscript received February 13, 1989; revised manuscript received and accepted Avril 18. 1989.
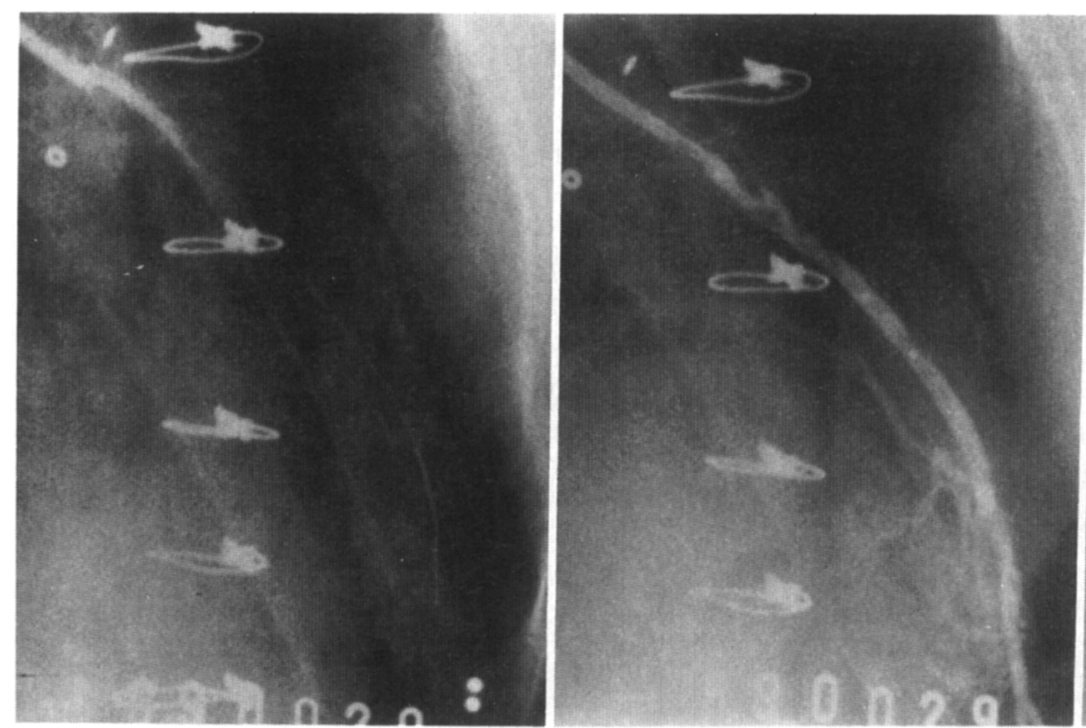

most distal anastomosis, and a distal anastomosis was located in the distal part of the graft. Single grafts were placed in the other 4 patients (1 to 3/patient). The mean period between bypass surgery and angioplasty was 5.9 \pm 4 years (range 0.25 to 12). The estimated duration of graft occlusion varied between 3 and 6 months except for patients who presented with acute myocardial infarction.

Angioplasty was attempted by the femoral approach in all patients. In 3 patients a balloon catheter with a fixed flexible guidewire at the tip (Schneider-Medintag) was used according to the technique described by Grüntzig. In the remaining 12 patients a guidewire was used to cross the lesion, then the balloon catheter was advanced across the stenosis and a series of 3 to 17 balloon inflations (mean $7 \pm 4$ ) were carried out at pressures varying from 2 to 14 atmospheres (mean $11 \pm 3$ ). The total inflation time varied from 155 to 970 seconds (mean 423 \pm 280 ). The maximal balloon size used varied from 2.0 to $4.2 \mathrm{~mm}$ (mean $3.0 \pm 1$ ). A procedure was considered successful if (1) the total occlusion was reduced to a luminal narrowing <50\%; (2) no major complication occurred (myocardial infarction, death or acute surgery); and (3) there was no recurrence of reocclusion during hospitalization. Data are expressed as mean \pm 1 standard deviation.

In 1 patient the lesion could not be crossed with the wire. In the remaining 14 patients it proved relatively easy to perforate and cross the total occlusion with the wire and the balloon. However. in 4 patients the stenosis

FGURE 1. Left, totaly occhuded graft in proximal part of shgie graft to the lef anterior descending coronary artery.

The occludion is perforated with a floppy guidewire. Center, graft after perforation and dilatation shows irregularities, haxiness and dissection. Right, smooth appearance of graft after placement of 2 stents. 


\begin{tabular}{|c|c|c|c|c|c|c|c|c|c|c|}
\hline Pt & $\begin{array}{l}\text { Age (yrs), } \\
\text { Sex }\end{array}$ & $\begin{array}{l}\text { Anginal } \\
\text { Status } \\
\text { (NYHA) }\end{array}$ & $\begin{array}{l}\text { No. } \\
\text { CAD } \\
50 \% \\
\text { Luminal } \\
\text { Diameter }\end{array}$ & $\begin{array}{l}\text { Interval } \\
\text { CABG- } \\
\text { PTA } \\
\text { (yrs) }\end{array}$ & $\begin{array}{l}\text { Type } \\
\text { of } \\
\text { Graft }\end{array}$ & $\begin{array}{l}\text { Site of } \\
\text { Occlusion }\end{array}$ & $\begin{array}{l}\text { STK } \\
\text { IB }\end{array}$ & $\begin{array}{l}\text { Angio- } \\
\text { graphic } \\
\text { Success }\end{array}$ & Complication & $\begin{array}{l}\text { Angiographic } \\
\text { Reocclusion } \\
\text { (wks) }\end{array}$ \\
\hline 1 & $52, \mathrm{M}$ & 11 & 3 & 6 & Jump & Distal & - & 一 & - & \\
\hline 2 & $70, M$ & II & 3 & 12 & Single & Proximal & - & + & Embolus / AMI/CK (684 IU) & $+(1)$ \\
\hline 3 & $42, \mathrm{M}$ & III & 3 & 5 & Jump & Proximal & - & + & - & $+(4)$ \\
\hline 4 & $58, \mathrm{M}$ & III & 3 & 12 & Single & Proximal & + & + & - & $+(0.2)$ \\
\hline 5 & $46, M$ & III & 3 & 1.2 & Jump & Middle & + & + & - & $+(1)$ \\
\hline 6 & $59, \mathrm{M}$ & III & 3 & 0.5 & Jump & Proximal & - & 一 & - & \\
\hline 7 & $45, M$ & III & 3 & 0.25 & Jump & Distal & - & - & Wire not crossed & \\
\hline 8 & $71, \mathrm{~F}$ & III & 3 & 8 & Jump & Middle & - & + & - & $-(25)$ \\
\hline 9 & $68, F$ & III & 2 & 9 & Single & Proximal & - & + & Embolus, AMI/CK (280 IU) & $+(0.2)$ \\
\hline 10 & $73, \mathrm{M}$ & III & 3 & 1 & Jump & Proximal & - & - & - & \\
\hline 11 & 57. M & IV & 2 & 8.5 & Jump & Middle & + & - & $\begin{array}{l}\text { Embolus/AMI/Shock/IABP/CK } \\
(1,200 \mathrm{lU})\end{array}$ & \\
\hline 12 & $61 . F$ & IV & 3 & 10 & Single & Proximal & + & + & Embolus/AMI/CK (800 IU) & $+(8)$ \\
\hline 13 & 55. M & IV & 3 & 3.5 & Jump & Middle & - & 一 & Embolus/AMI/CK (148IU) & \\
\hline 14 & $60, M$ & AMI & 2 & 5.5 & Jump & Middle & - & + & Embolus/AMI/CK $(2,875 \mathrm{IU})$ & $+(0.2)$ \\
\hline 15 & $54, \mathrm{M}$ & AMI & 1 & 9 & Jump & Middle & + & + & CK $(900 \mathrm{IU})$ & $+\mathrm{AMI}(12)$ \\
\hline
\end{tabular}

was undilatable due to immediate "collapse" of the stenosis even after repeated dilatations with oversized balloons. The procedure was initially successful in $4 \mathrm{pa-}$ tients (27\%), but angiographically proven early reocclusion occurred in 2 of these patients and 1 patient developed a new reinfarction in the same myocardial territory of the previously dilated graft.

In 5 patients, following clot formation, streptokinase $(500,000$ to $750,000 \mathrm{U})$ was infused into the graft during the procedure in an attempt to maintain patency. However, this did not prevent early reocclusion in these patients. Embolization with subsequent myocardial necrosis occurred in 6 patients. Due to the negative results in the previous patients, we tried in patient 15 (the last one in our series) to prevent reocclusion with the implantation of 2 stents. Although the initial result was acceptable (except for a distal embolus) and despite intensive anticoagulant treatment, the graft was totally occluded the following day (Figure 1). Thus, an initial and longterm success was achieved in only 1 of the 15 patients. The short-and long-term results could not be related to the status of the native coronary arteries (diffuse sclerotic disease, proximal occlusion), collateral flow to the target artery or ventricular myocardium subserved by the graft (normal, hypokinetic or akinetic).

Although coronary artery bypass grafting is highly successful in the relief of angina pectoris in patients with coronary artery disease, autogenous saphenous vein grafts undergo varying degrees of intimal proliferative or other degenerative changes with subsequent recurrent angina pectoris. The attrition rate at 1 year is approximately $15 \%$ and it increases over the years. At the end of 10 years, slightly more than half of the vein grafts are occluded (as shown by angiography) and, of those that remain open, about half show evidence of vein graft atherosclerosis. ${ }^{6,7}$
This implies a substantial number of patients with totally occluded grafts who would be potential candidates for revascularization. Although reoperation can be performed with satisfactory results, the technical difficulty, morbidity, mortality and complications for a second and subsequent procedure are more frequent. ${ }^{8}$

Therefore, percutaneous transluminal angioplasty is potentially an attractive alternative to repeat surgery. Only scant reported information is available about angioplasty of totally occluded bypass grafts. ${ }^{2,6,9}$ Finci et $\mathrm{al}^{9}$ described a patient who underwent a successful procedure, but follow-up data are lacking. In our experience, it was surprisingly easy to perforate and cross the total occlusion with the wire and the balloon. This suggests that the occlusions consist of rather loosely organized material, which can be easily traversed but which also tends to "collapse." This explains why the lesion was "undilatable" in 4 patients. There is also an increased risk of thromboembolism during passage with the balloon catheter, which occurred in 6 of the 15 patients in our study and which has also been noted by others. ${ }^{10}$

This risk is probably increased because atherosclerosis in vein grafts tends to involve dilated segments and to be more friable and less fibrocalcific than the counterpart in the native coronary arteries. Therefore, the grafts are particularly vulnerable to disruption and to embolization of relatively large fragments. This is similar to the increased risk of perioperative myocardial infarction caused by atheroembolization during repeat coronary artery bypass surgery.

The early reocclusion after an angiographic successful dilatation that occurred in nearly all patients and the early "collapse" suggest rethrombosis rather than intimal fibrocellular proliferation or progressive atherosclerosis as the cause. In 1 patient, the implantation of stents also failed to prevent early reocclusion. The high frequency 
of early reocclusion is probably related to the lack of a normal endothelium within these severely diseased grafts. $^{10}$

Thus, although angioplasty of a totally occluded saphenous vein graft is challenging, the outcome is so poor that the temptation to dilate should be resisted. The result may well be different for occlusions in grafts not older than 1 month because in such cases the occlusion almost always is due to thrombosis and usually is related to technical factors, such as anastomotic narrowing or operative trauma to vein graft.

1. Douglas JS Jr, Gruentzig AR, King SB, Hollman J, Ischinger $T$, Meier $B$, Craver JM, Jones EL, Waller JL, Bone DK, Guyton R. Percutaneous transluminal coronary angioplasty in patients with prior coronary bypass surgery. $J A C C$ 1983:2:745-754.

2. Dorros G, Johnson WD, Tector AJ, Schmahl TM, Kalush SL, Janke L Percutaneous transluminal coronary angioplasty in patients with prior coronary artery bypass grafting. J Thorac Cardiovase Surg 1984,87:17-26.

3. Dervan JP, Baim DS, Cherniles J, Grossman W. Transluminal angioplasty of occluded coronary arteries: use of a movable guide wire system. Circulation
1983,68:776-784.

4. Kereiakes DJ, Selmon MR. McAuley BJ, McAuley DB, Sheehan DJ, Simpson JB. Angioplasty in total coronary artery occlusion: experience in 76 consecutive patients. JACC 1985,6:526-533.

5. Serruys PW, Umans V, Heyndrickx GR, van den Brand M, de Feyter PJ, Wijns W, Jaski B, Hugenholtz-PG. Elective PTCA of totally occluded coronary arteries not associated with acute myocardial infarction; short-term and long-term results. Eur Heart J 1985,6:2-12.

6. Campeau L, Enjalbert M, Lesperance J, Bourassa MG, Kwiterovich P, Wachdder S, Sniderman A. The relation of risk factors to the development of atherosclerosis in saphenous-vein bypass grafts and the progression of disease in the native circulation: a study 10 years after aortocoronary bypass surgery. $N$ Engl $J$ Med 1984;311:1329-1332.

7. De Feyter PJ, Serruys PW, Brower RW, van den Brand M, Ten Katen HJ, Hugenholtz PG, Bos E. Comparison of preoperative, operative and postoperative variables in asymptomatic or minimally symptomatic patients to severely symptomatic patients three years after CABG: analysis of 423 patients. Am J Cardiol 1985:55:362-366.

8. Reul GJ, Cooley DA, Ott DA, Coehlo A, Chapa L, Eterovic I. Reoperation for recurrent coronary artery disease, causes, indications and results in 168 patients. Arch Surg 1979:114:1269-1275.

9. Finci L, Meier B, Steffenino GD. Percutaneous angioplasty of totally occluded saphenous aortocoronary bypass graft. Int $J$ Cardiol 1986;10:76-79.

10. Saber RS, Eduards WD, Holmes DR, Vlietstra RE, Reeder GS. Balloon angioplasty of aortocoronary saphenous vein bypass grafts: a histopathologic study of six grafts from five patients, with emphasis on restenosis and embolic complications. JACC 1988;12:1501-1509.

\section{Effect of a Media Campaign on Delay Times and Ambulance Use in Suspected Acute Myocardial Infarction}

Johan Herlitz, MD, Marianne Hartford, MD, Marianne Blohm, RN, Bjorn W. Karlson, MD, Lars Ekström, MD, Martin Risenfors, MD, Bertil Wennerblom, MD, Russell V. Luepker, MD, and Stig Holmberg, MD

$\mathbf{T}$ he early phase in suspected acute myocardial infarction (AMI) is particularly critical. More than $50 \%$ of deaths from coronary artery disease occur outside the hospital mainly due to ventricular fibrillation. ${ }^{1}$ Recent experiences strongly indicate that early intervention with thrombolysis ${ }^{2-4}$ and $\beta$ blockers ${ }^{5,6}$ can limit myocardial damage and thereby improve prognosis. Delay times in suspected AMI have remained stable over the years. Therefore, a media campaign was started in the urban area of Göteborg, Sweden, with the intention to shorten delay times and to increase ambulance use in patients with suspected AMI.

Between February 15, 1986, and November 9, 1987. all patients presenting with chest pain or other symptoms suggestive of AMI at the emergency room of the Sahlgrenska Hospital lin Gôteborg were evaluated by emergency room physicians who used a specified protocol. Patients were prospectively classified into 4 categories in the emergency room according to the following definitions: (1) obvious AMI, defined as typical symptoms and changes of $S T$-segment elevation with or without $Q$ waves in the initial 12-lead electrocardiogram; (2) strong suspicion of AMI, including either (a) typical symptoms but an inconclusive electrocardiogram, $(b)$

From the Division of Cardiology, Department of Medicine I, Sahlgrenska Hospital, University of Göteborg, S-413 45 Göteborg, Sweden. This study was supported by grants from the Swedish National Association Against Heart and Chest Diseases. Manuscript received February 16, 1989; revised manuscript received and accepted April 19, 1989.
TABLE I Number of Patients Arriving Daily in the Emergency Room Due to Chest Pain, Before and During the First Four Months of the Campaign

\begin{tabular}{|llllll|}
\hline & Before & $\begin{array}{l}\text { First } \\
\text { Month }\end{array}$ & $\begin{array}{l}\text { Second } \\
\text { Month }\end{array}$ & $\begin{array}{l}\text { Third } \\
\text { Month }\end{array}$ & $\begin{array}{l}\text { Fourth } \\
\text { Month }\end{array}$ \\
\hline All patients & 11.3 & 19.6 & 13.1 & 12.4 & 13.8 \\
Category & & & & & \\
1 & 0.4 & 0.4 & 0.3 & 0.3 & 0.3 \\
2 & 2.3 & 2.7 & 2.1 & 2.1 & 2.5 \\
3 & 4.0 & 6.3 & 4.9 & 4.2 & 4.2 \\
4 & 4.6 & 10.2 & 5.8 & 5.8 & 6.9 \\
Patients with AMI* & 1.5 & 1.8 & 1.9 & 1.2 & 1.6 \\
\hline "Based on the final diagnosis. & & & & \\
\hline
\end{tabular}

sudden onset of severe congestive heart failure with inconclusive electrocardiogram, (c) atypical symptoms but $S T$ changes or $Q$ waves on the electrocardiogram or (d) unstable angina pectoris; (3) vague suspicion of $A M I$ defined as atypical pain and no changes in the electrocardiogram; and (4) no suspicion of AMI, indicated by (a) noncardiac diagnosis, $(b)$ nonischemic cardiac diagnosis or (c) stable angina pectoris.

In all admitted patients, the delay time between onset of symptoms and arrival at hospital was recorded. All the patients in this population participated in a prospective study presented elsewhere.

AMI was defined if 2 of the following criteria were fulfilled: (1) chest pain with a duration >15 minutes; (2) elevated serum aspartate aminotransferase and creatine 